\title{
CFTR mutations and IVS8-5T variant in newborns with hypertrypsinaemia and normal
} sweat test

\author{
C Castellani, A Bonizzato, G Mastella
}

\begin{abstract}
Neonates positive for immunoreactive trypsinogen assay (IRT) and negative for sweat test have formerly been found to carry the major cystic fibrosis (CF) mutation, $\triangle F 508$, much more frequently than the general population. Among the 716 IRT positive newborns detected by a three tier (IRT, mutation analysis plus meconium lactase assay, sweat test) CF screening programme in north eastern Italy during the period January 1993 to March 1996, we found 45 carriers, a number significantly higher than the expected 17 $(p<0.001)$. We speculated that some of these heterozygotes could actually be affected by a very mild form of CF, and carry on the other chromosome an undetected CFTR mutation or a DNA variant, such as the 5-thymidine allele in intron 8 of the CFTR gene (IVS8-5T). This hypothesis was tested in four samples: group $A$ (the 45 carriers mentioned above), group B (51 non-carrier, IRT positive neonates), group C (50 IRT negative neonates), and group D (90 CF adult female carriers). Chromosomes with IVS8-5T were seven $(7.78 \%)$ in group $A$, seven $(6.86 \%)$ in group B, five (5\%) in group C, and four in group $D(2.22 \%)$. The $5 T$ prevalence in group A was significantly higher $(p<0.05)$ compared to group D; similarly, a higher $(p<0.05) 5 T$ frequency in group A compared to group $\mathbf{C}$ was detected by considering the chromosomes free from CFTR mutations. This study is consistent with previous papers in finding among neonates with high trypsin levels a CF carrier frequency significantly higher than that expected. It is also suggested that in at least some babies raised trypsin levels at birth could be a phenotypic expression of compound heterozygosity for a major CF mutation plus IVS8-5T.
\end{abstract}

(F Med Genet 1997;34:297-301)

Cystic Fibrosis Maggiore, Piazzale Stefani, 37126 Verona, Italy

C Castellani

A Bonizzato

G Mastella

Correspondence to: Dr Castellani.

Received 25 June 1996 Revised version accepted for publication 22 October 1996 (IRT) in dried blood now the most common technique for cystic fibrosis (CF) neonatal screening. ${ }^{1}$ Since a considerable number of unaffected newborns show raised IRT levels, several laboratories have chosen to improve the screening specificity by introducing mutation analysis for infants with hypertrypsinaemia. As a consequence of genetic testing, a few CF carriers are detected, and in the past unaffected IRT positive babies have been unexpectedly found to carry the major CF mutation, $\triangle F 508$, much more frequently than the general population. ${ }^{2}{ }^{3}$ It has therefore been postulated ${ }^{2}{ }^{3}$ that IRT could indirectly detect some heterozygotes.

An alternative explanation could be that at least some of these babies are actually affected, and carry on the other chromosome a mild mutation or a DNA variant, associated with few symptoms and normal sweat chloride values. A possible candidate for this role is a DNA polymorphic sequence of five thymines in intron 8 of the cystic fibrosis transmembrane conductance regulator (CFTR) gene. The 5-thymidine allele (IVS8-5T), in contrast to the more common $7 \mathrm{~T}$ and $9 \mathrm{~T}$ variants, is responsible for low levels of normal CFTR mRNA, and has been very frequently found in men with a form of infertility called congenital bilateral absence of the vas deferens (CBAVD), a condition which has been suggested to be a primarily genital form of $\mathrm{CF}^{4-6}$

We report here data obtained in the genetic screening of some frequent CFTR mutations plus the 5T allele in 96 IRT positive neonates.

\section{Materials and methods}

SCREENING STRATEGY

The results of CF neonatal screening in north eastern Italy from January 1993 to March 1996 were reviewed. The screening strategy used a three tier system, whose progressive steps were immunoreactive trypsinogen (IRT), mutation analysis with complementary meconium lactase determination, and sweat test. IRT levels were measured in dried blood spot specimens from neonates born in the Veneto and Trentino-Alto Adige regions. An immunoreactive trypsinogen concentration of $100 \mu \mathrm{g}$ trypsin/1 whole blood, lowered in May 1995 to $95 \mu \mathrm{g} / 1$ (equal to the 99.5 th centile for an unselected neonatal population of 7223), was chosen as the cut off point. At or above this value, mutation analysis and meconium lactase determination were performed. Initially we tested for $\Delta \mathrm{F} 508, \mathrm{R} 1162 \mathrm{X}$, and N1303K, estimated by a cohort study ${ }^{7}$ to cover $61 \%$ of CF chromosomes in our area; from March 199510 other mutations were included (2183AAG, 3849+10KbCT, G542X, 1717-1GA, R553X, Q552X, G85E, 711+5GA, 3132delTG, 
$2789+5 \mathrm{GA}$ ), thus covering $85 \%$ of $\mathrm{CF}$ mutations. $^{7}$

Diagnosis was immediately established in neonates, either homozygous or compound heterozygous, who were referred directly for clinical management of CF. If either one mutation tested positive or meconium lactase was above the cut off level of $0.5 \mathrm{U} / \mathrm{l}$, a sweat test, which is regarded as the definitive test for $\mathrm{CF}$, was immediately performed on the infant, thus discriminating between affected and unaffected subjects. In neonates with borderline chloride levels, sweat test was repeated in order to achieve either clearly positive or negative results. Sweat test was always associated with clinical evaluation, and frequently also with IRT retesting and fecal chymotrypsin determination.

The families of carriers detected incidentally were offered genetic counselling and gene analysis.

\section{POPULATION UNDER STUDY}

The CFTR gene variants of $T$ tract length of intron 8 were determined in 236 subjects, all from the same geographical area, who were divided into four groups. Group A: 45 neonates who were IRT positive, carried one of the mutations screened for, but whose sweat test result was normal; group B: 51 neonates with high trypsin levels $(>95 \mathrm{~g} / \mathrm{l})$ but no mutation detected; group C: 50 neonates with low trypsin levels, who were supposed to be representative of the general population poly $T$ sequence distribution pattern; group D: 90 adults, who carried the same CFTR mutations as newborns in group A (every baby was matched to two adults with the same mutation), chosen from among first or second degree relatives of 90 unrelated CF patients. Only female relations were included in the last group, as the $5 \mathrm{~T}$ allele is suggested to be significantly less frequent in the chromosomes of fathers of patients with CF, and therefore in male carriers, than in the general population. ${ }^{4}$

A plan for follow up of infants belonging to the first group and found to carry the $5 \mathrm{~T}$ allele is being developed.

\section{ANALYTICAL PROCEDURES}

Immunoreactive trypsin was assayed by the Pharmacia standardised Delfia Neonatal IRT kit. ${ }^{8}$ Meconium lactase activity was determined as previously described. ${ }^{9}$ Dried blood spots on Guthrie cards were the sources of DNA. The procedure used to prepare DNA for PCR, based on those described by Singer-Sam et al ${ }^{10}$ and Walsh et $a l^{11}$ for forensic material, is very simple and requires only boiling cells in a 5\% suspension of chelating resin (Sigma, St Louis, MO).

During the period January 1993 to February 1995 mutations were analysed by restriction enzymes as previously described, ${ }^{12}$ or by heteroduplex analysis (for $\Delta \mathrm{F} 508$ ) according to Rommens et $a l^{13}$; from March 1995 we switched to a reverse dot blot assay. ${ }^{14}$ The intron 8 poly $T$ sequence was analysed with the nested PCR method according to Chillon et al. ${ }^{4}$ The confirmatory sweat electrolyte analysis was performed at least twice by the classical method of Gibson and Cooke. ${ }^{15}$ Chloride levels above $60 \mathrm{mEq} / \mathrm{kg}$ were considered as positive, between 40 and $60 \mathrm{mEq} / \mathrm{kg}$ as borderline, and below $40 \mathrm{mEq} / \mathrm{kg}$ as negative, provided that the amount of sweat collected was at least $50 \mathrm{mg}$ for a stimulation/collection skin area of $3.2 \times$ $3.2 \mathrm{~cm}$.

Comparison of the detected and expected carrier frequencies was performed by normal approximation to binomial distribution. The groups under study were analysed using Fisher's exact test.

\section{Results}

A total of 154637 newborns were screened, of whom 716 were IRT positive $(0.46 \%)$. Among these we found 58 affected subjects (median chloride $99 \mathrm{mEq} / \mathrm{kg}$, range 61-121; observed $\mathrm{CF}$ incidence $1 / 2666$ ) and 45 carriers (median chloride $20 \mathrm{mEq} / \mathrm{kg}$, range 6-39). Two babies, both carrying a CFTR mutation but not the $5 \mathrm{~T}$ variant, showed repeatedly borderline sweat chloride levels: they are being closely followed, but so far we cannot say whether they are affected or not and they have not been included in our figures.

The carrier frequency of $1 / 15$ (29/429) observed when we tested for three mutations is significantly higher $(p<0.001)$ than the expected $1 / 44$ for the same mutations. A significant difference $(p<0.001)$ was also found after we decided to screen for 13 mutations, when the observed carrier frequency was $1 / 14$ $(16 / 227)$ against the expected $1 / 32 .^{7}$ By combining the data from the two periods, the expected number of carriers in a population of $656(429+227)$ would be 17 , a figure which is again much lower than the detected number of $45(\mathrm{p}<0.001)$.

The 5 T allele was found in $7 / 45$ (15\%) IRT positive neonates carrying a CF mutation, in $7 / 51(13 \%)$ IRT positive neonates not carrying any of the sought CF mutations, in $5 / 50(10 \%)$ IRT negative neonates, and in 4/90 (4\%) adult carriers (table 1 ). The $5 \mathrm{~T}$ incidence in groups $\mathrm{C}$ and $\mathrm{D}$ is similar to that previously reported in control populations from different geographical areas. ${ }^{46-18}$ The frequency of the $5 \mathrm{~T}$ allele gradually decreased from group A to group $D$, with a significant difference between $A$ and $D(p=0.0459)$. In the seven babies who carried both IVS8-5T and a CF mutation, the latter was always $\Delta \mathrm{F} 508$; in the four adults the mutations were $\Delta \mathrm{F} 508$ (twice), N1303K, and R1162X.

Table 2 shows IRT and meconium lactase, plus CFTR and polyT genotypes found in group A. Sweat chloride values and concomitant IRT and weight $\mathrm{Z}$ score are also included. In all but one (No 26) cases in which data were available, blood trypsinogen levels showed a time related decrease not consistent with CF. No definite failure to thrive or lung disease symptoms were found at the time of sweat test in any of the subjects who could be clinically evaluated, with the exception of subject 5 , a severely premature baby. Both subjects 43 and 45 underwent surgery, the former because of a 
Table 1 Frequencies of the polyT alleles in intron 8 of CFTR in the groups under study

\begin{tabular}{|c|c|c|c|c|}
\hline & Description & $\begin{array}{l}5 T \text { allele } \\
(\%)\end{array}$ & $\begin{array}{l}7 T \text { allele } \\
(\%)\end{array}$ & $\begin{array}{l}9 T \text { allele } \\
(\%)\end{array}$ \\
\hline $\begin{array}{l}\text { Group } \\
\text { A }\end{array}$ & $\begin{array}{l}\text { Newborns IRT } \\
\text { positive at birth } \\
1 \text { CFTR } \\
\text { mutation detected } \\
\text { Normal sweat } \\
\text { chloride }\end{array}$ & $\begin{array}{l}7 / 90 \\
(7.78)^{\star}\end{array}$ & $\begin{array}{l}44 / 90 \\
(48.89)\end{array}$ & $\begin{array}{l}39 / 90 \\
(43.33)\end{array}$ \\
\hline $\begin{array}{l}\text { Group } \\
\text { B }\end{array}$ & $\begin{array}{l}\text { Newborns IRT } \\
\text { positive at birth } \\
\text { No CFTR } \\
\text { mutation detected }\end{array}$ & $\begin{array}{l}7 / 102 \\
(6.86)\end{array}$ & $\begin{array}{l}81 / 102 \\
(79.41)\end{array}$ & $\begin{array}{l}14 / 102 \\
(13.73)\end{array}$ \\
\hline $\begin{array}{l}\text { Group } \\
\text { C } \\
\text { Group } \\
\text { D }\end{array}$ & $\begin{array}{l}\text { Newborns IRT } \\
\text { negative at birth } \\
\text { Adults (female } \\
\text { CF relatives) } 1 \\
\text { CFTR mutation } \\
\text { detected }\end{array}$ & $\begin{array}{l}5 / 100 \\
(5) \\
4 / 180 \\
(2.22)^{\star}\end{array}$ & $\begin{array}{l}85 / 100 \\
(85) \\
97 / 180 \\
(53.89)\end{array}$ & $\begin{array}{l}10 / 100 \\
(10) \\
79 / 180 \\
(43.89)\end{array}$ \\
\hline
\end{tabular}

congenital heart defect, the latter for Hirschsprung's disease.

\section{Discussion}

The raised IRT levels in infants with CF are thought to be the result of "leakage" of trypsinogen into the bloodstream, derived from functioning, but ductally obstructed, pancre- atic tissue. ${ }^{19}$ Both pancreatic insufficient and, to a lesser extent, pancreatic sufficient subjects with CF can be identified by the IRT assay. ${ }^{20} 21$

However, neonatal hypertrypsinaemia also occurs in many unaffected infants. ${ }^{1922}$ High IRT levels in seemingly normal babies have not yet been fully explained: even though some pathological conditions such as perinatal asphyxia seem to cause false positive screening results, ${ }^{23}$ many newborns have no real cause for their hypertrypsinaemia.

This study is consistent with previous papers from other authors ${ }^{2}$ in finding among neonates with high trypsin levels a CF carrier frequency significantly higher than the expected one: testing for three mutations one newborn in every 15 was a carrier, instead of the anticipated $1 / 44$. When we expanded the analysis to 13 mutations, again one newborn in every 14 was found to be a carrier, against the expected $1 / 32 .^{7}$ Considering the two mutation analysis periods as a whole, there is again a significant difference between the 17 expected and the 45 carriers actually found.

The explanation for such a peculiar phenomenon is a matter for conjecture. One possibility could be that neonatal IRT positivity is capable of indirectly detecting some heterozygotes who

Table 2 Screening and genotype data in group $A$. The IRT retest and weight $Z$ score are reported when available, and refer to a mean age of 38 days (range 22-90). Normal values for IRT and IRT retest were considered respectively as below 100 (95 from May 1995 onwards) and $75 \mu \mathrm{g} / \mathrm{l}$. Meconium lactase threshold was $0.5 \mathrm{U} / \mathrm{g}$. Bold type is used for neonates carrying the $5 T$ variant.

\begin{tabular}{|c|c|c|c|c|c|c|c|c|}
\hline Subject & $\operatorname{Sex}$ & $\begin{array}{l}I R T \\
(\mu g / l)\end{array}$ & $\begin{array}{l}\text { Meconium } \\
\text { lactase (U/g) }\end{array}$ & $\begin{array}{l}\text { Sweat } \\
\text { chloride } \\
\text { (mEq/kg) }\end{array}$ & CFTR mutation & $\begin{array}{l}\text { PolyT } \\
\text { genotype }\end{array}$ & $\begin{array}{l}I R T \text { retest } \\
(\mu g / l)\end{array}$ & $\begin{array}{l}\text { Weight } Z \\
\text { score }\end{array}$ \\
\hline 1 & $\mathrm{~F}$ & 134 & 0 & 6 & $\Delta \mathrm{F} 508$ & $7 / 9$ & 67 & 1.47 \\
\hline 2 & M & 95 & 0 & 28 & $\Delta \mathrm{F} 508$ & $7 / 9$ & & \\
\hline 3 & $\mathrm{~F}$ & 408 & 0 & 7 & $2183 \mathrm{AA} \rightarrow \mathrm{G}$ & $7 / 7$ & 14 & -0.29 \\
\hline 4 & $M$ & 150 & 0.72 & 16 & N1303K & $7 / 9$ & 19 & -0.47 \\
\hline 5 & $\mathrm{~F}$ & 106 & Unknown & 18 & R1162X & $7 / 7$ & & -6.38 \\
\hline 6 & $M$ & 131 & 0 & 22 & N1303K & $9 / 9$ & 27 & -0.54 \\
\hline 7 & $M$ & 106 & 0 & 21 & $\Delta \mathrm{F} 508$ & $7 / 9$ & 34 & 0.11 \\
\hline 8 & $\mathbf{F}$ & 100 & 0 & 15 & $\Delta F 508$ & $5 / 9$ & 37 & -0.01 \\
\hline 9 & $\mathbf{F}$ & 105 & 0 & 25 & $\Delta F 508$ & $5 / 9$ & 51 & -0.15 \\
\hline 10 & $\mathrm{~F}$ & 100 & 0 & 24 & R1162X & $7 / 7$ & & \\
\hline 11 & M & 266 & 0 & 14 & $\Delta \mathrm{F} 508$ & $7 / 9$ & 5 & 0.20 \\
\hline 12 & $\mathrm{~F}$ & 103 & 0 & 9 & $\Delta \mathrm{F} 508$ & $7 / 9$ & & \\
\hline 13 & $\mathrm{~F}$ & 105 & 0 & 32 & $\Delta \mathrm{F} 508$ & $7 / 9$ & & \\
\hline 14 & $\mathrm{~F}$ & 268 & 0 & 22 & $\Delta \mathrm{F} 508$ & $7 / 9$ & 30 & \\
\hline 15 & $M$ & 110 & Unknown & 33 & R1162X & $7 / 7$ & & \\
\hline 16 & $M$ & 174 & 0 & 12 & $\Delta \mathrm{F} 508$ & $7 / 9$ & 52 & 1.87 \\
\hline 17 & $\mathrm{~F}$ & 100 & 0 & 15 & $\Delta \mathrm{F} 508$ & $7 / 9$ & & \\
\hline 18 & M & 140 & 0 & 9 & $\Delta \mathrm{F} 508$ & $7 / 9$ & & \\
\hline 19 & $\mathbf{M}$ & 98 & $\mathbf{0}$ & 30 & $\Delta$ F508 & $5 / 9$ & & \\
\hline 20 & M & 110 & 1.2 & 10 & $\Delta \mathrm{F} 508$ & $7 / 9$ & 11 & 0.26 \\
\hline 21 & $\mathrm{~F}$ & 102 & 0 & 20 & G542X & $7 / 9$ & 45 & 0.77 \\
\hline 22 & $\mathrm{~F}$ & 111 & 0 & 16 & N1303K & $7 / 9$ & & \\
\hline 23 & $\mathrm{~F}$ & 100 & 0 & 16 & $\Delta \mathrm{F} 508$ & $7 / 9$ & 54 & -0.44 \\
\hline 24 & $\mathrm{~F}$ & 95 & 0 & 18 & R553X & $7 / 9$ & & \\
\hline 25 & $\mathrm{~F}$ & 285 & 0 & 16 & $\Delta \mathrm{F} 508$ & $7 / 9$ & 20 & 0.28 \\
\hline 26 & $M$ & 117 & 0 & 23 & $\Delta \mathrm{F} 508$ & $7 / 9$ & 101 & \\
\hline 27 & $\mathbf{M}$ & 115 & 0 & 24 & $\Delta F 508$ & $5 / 9$ & 12 & -0.4 \\
\hline 28 & $\mathrm{~F}$ & 236 & 0 & 8 & $\Delta \mathrm{F} 508$ & $7 / 9$ & 21 & 0.26 \\
\hline 29 & $M$ & 192 & 0 & 19 & N1303K & $7 / 9$ & 73 & 0.04 \\
\hline 30 & $\mathbf{M}$ & 103 & $\mathbf{0}$ & 39 & $\Delta F 508$ & $5 / 9$ & 69 & \\
\hline 31 & M & 133 & 0 & 10 & $\Delta \mathrm{F} 508$ & $7 / 9$ & 65 & 1.17 \\
\hline 32 & M & 144 & 0 & 30 & R1162X & $7 / 7$ & 74 & -0.83 \\
\hline 33 & $\mathrm{~F}$ & 123 & 0 & 20 & $\Delta \mathrm{F} 508$ & $7 / 9$ & 66 & -0.02 \\
\hline 34 & $\mathbf{F}$ & 100 & Unknown & 30 & $\Delta F 508$ & $5 / 9$ & 65 & \\
\hline 35 & M & 134 & 0 & 28 & $\Delta \mathrm{F} 508$ & $7 / 9$ & & \\
\hline 36 & M & 294 & 0.8 & 12 & R553X & $7 / 7$ & & \\
\hline 37 & M & 102 & Unknown & 32 & $2789+5 G \rightarrow A$ & $7 / 7$ & & \\
\hline 38 & $\mathrm{~F}$ & 114 & 0 & 36 & $\Delta \mathrm{F} 508$ & $7 / 9$ & & \\
\hline 39 & $\mathbf{M}$ & 123 & 0 & 9 & R1162X & $7 / 7$ & 51 & -0.36 \\
\hline 40 & $\mathbf{F}$ & 118 & o & 33 & $\Delta \mathrm{F} 508$ & $5 / 9$ & 16 & 0.18 \\
\hline 41 & $M$ & 134 & 0 & 10 & $\Delta \mathrm{F} 508$ & $7 / 9$ & 15 & 1.36 \\
\hline 42 & M & 97 & 0 & 9 & $\Delta \mathrm{F} 508$ & $7 / 9$ & & \\
\hline 43 & M & 98 & 1.71 & 31 & $\Delta \mathrm{F} 508$ & $7 / 9$ & & \\
\hline 44 & $\mathrm{~F}$ & 122 & Unknown & 23 & $\Delta \mathrm{F} 508$ & $7 / 9$ & & \\
\hline 45 & $\mathrm{~F}$ & 101 & 0 & 23 & $\Delta \mathrm{F} 508$ & $9 / 9$ & & \\
\hline
\end{tabular}


show mild biological abnormalities as early as the first days of life. However, carriers have always been considered to be clinically and biologically asymptomatic, and it is difficult to explain why some of them show this feature while others do not.

Alternatively, either the carrier frequency in the general population could be more than the calculated one, or the relative frequency of the tested mutations could be higher. Both options are unlikely, the former because such a huge number of carriers would be consistent with an incidence of $\mathrm{CF}$ much greater than that currently observed, the latter because we have previously shown the distribution of CF mutations in our population by characterising more than $90 \%$ of the mutated alleles from a cohort of $225 \mathrm{CF}$ chromosomes.

Finally, one could postulate that at least some of these newborns carry an undetectable mild mutation or a DNA variant on the other chromosome, associated with normal sweat chloride values, but capable of raising trypsin levels.

A polymorphic repeat which could play this role is the 5-thymidine allele in intron 8 . The proportion of the exon 9 transcript is inversely related to the length of the poly-thymidine tract in the sequence of the acceptor splice site of intron 8, the $5 \mathrm{~T}$ allele causing a high proportion of an abnormal, alternatively spliced CFTR mRNA. ${ }^{24}$ Subjects with one CF mutation on one chromosome and the $5 \mathrm{~T}$ allele on the other have little normal CFTR, and their phenotypes are quite diverse, including mild $\mathrm{CF}$, disseminated bronchiectasis, CBAVD, and the absence of fertility problems. ${ }^{4526}$ We speculate that neonatal hypertrypsinaemia could also be included in this wide clinical spectrum. In fact, the prevalence of the 5T allele was only slightly higher in group A compared to B, and in B compared to $\mathrm{C}$.

The differences in the IVS8-5T frequencies would become much higher (group A $v \mathrm{C}$, $\mathrm{p}<0.05)$ if we considered two chromosomes per subject in groups B (7/102) and C (5/100) and only one chromosome per subject in group A $(7 / 45)$, according to the hypothesis that the $5 \mathrm{~T}$ variant is always in trans with $\Delta \mathrm{F} 508$. This assumption is supported by previous data, ${ }^{16}$ showing that $\Delta \mathrm{F} 508$ was linked to the $9 \mathrm{~T}$ allele in $85 \Delta$ F508 chromosomes. To the best of our knowledge, there are no published reports of a CFTR gene carrying both this mutation and the $5 \mathrm{~T}$ allele.

The $5 \mathrm{~T}$ phase relative to $\Delta \mathrm{F} 508$ was studied in four IRT positive babies whose parents agreed to be tested. $\Delta \mathrm{F} 508$ was never associated in $c$ is with the $5 \mathrm{~T}$ allele, thus supporting our hypothesis. However, using different numbers of chromosomes per person in the populations under comparison could be questionable. A more recognised approach to the study of empirical gene frequencies for a particular allele consists in calculating a ratio between the number of chromosomes positive for the allele and the total number of tested chromosomes, whether or not the status of the chromosomes regarding other mutations is known.

To follow this convention and at the same time overcome the difficulties connected with contrasting genetically heterogeneous populations like $\mathrm{A}, \mathrm{B}$, and $\mathrm{C}$, we chose to compare two samples of carriers, the IRT positive and CF heterozygous babies in group A and a control population of female CF carriers (group D). The significantly higher $(\mathrm{p}<0.05)$ prevalence of the IVS8-5T variant which we found in the former substantiates the hypothesis that some of these newborns are actually affected by a very mild form of $\mathrm{CF}$, thus explaining the high IRT levels. Similarly, it could be speculated that other CFTR variants or mild mutations were actually responsible for the hypertrypsinaemia in the remaining neonates in group $\mathrm{A}$ and, when affecting both chromosomes, in the ones in group B. A thorough study of the CFTR gene in these subjects should clarify the issue.

In conclusion, the incidence of CF carriers in infants with a raised IRT is higher than the one expected in the general population. In at least some babies raised trypsin levels at birth could be a phenotypic expression of compound heterozygosity for a major CF mutation plus the $5 \mathrm{~T}$ polymorphism. Considering the wide range of manifestations connected with this genotype, which can range from completely healthy to CBAVD or even mild CF, it is extremely difficult to predict the clinical outcome of these newborns, and to provide satisfactory genetic counselling for the family. Close clinical follow up should help in clarifying the extent of the disease in these subjects, with special regard to the three males, who could possibly turn out to be affected by CBAVD.

Newborn CF carriers with hypertrypsinaemia should perhaps deserve a closer look before being dismissed as "unaffected".

We are grateful to Nicoletta Zorzi for excellent technical assistance and to Giulio Cabrini for his review of the manuscript.

1 Dankert-Roelse JE. Neonatal screening. In: Dodge JA, Brock DJH, Widdicombe JH, eds. Cystic fibrosis - current topics. Chichester: Wiley, 1994:303-18.

2 Laroche $\mathrm{D}$, Travert $\mathrm{G}$. Abnormal frequency of $\Delta \mathrm{F} 508$ mutation in neonatal transitory hypertrypsinaemia. Lancet 1991;337:55.

3 Lucotte G, Perignon JL, Lenoir G. Transient neonatal hypertrypsinaemia as test for $\Delta \mathrm{F} 508$ heterozygosity. Lancet hypertrypsinaemic

4 Chillon M, Casals T, Mercier B, et al. Mutations in the cystic fibrosis gene in patients with congenital absence of the vas deferens. $N$ Engl F Med 1995;332:1475-80.

5 Oates RD, Amos JA. The genetic basis of congenital bilateral absence of the vas deferens and cystic fibrosis. $\mathcal{f}$ Androl 1994;15:1-8.

6 Patrizio P, Zielenski J. Congenital absence of the vas deferens: a mild form of cystic fibrosis. Mol Med Today 1996;2:24-31

7 Bonizzato A, Bisceglia L, Marigo M, et al. Analysis of the complete coding region of the CFTR gene in a cohort of CF patients from north-eastern Italy: identification of $90 \%$ of the mutations. Hum Genet 1995;95:397-402.

8 Cabrini G, Pederzini F, Perobelli L, Mastella G. An evaluation of an enzyme assay method for immunoreactive trypsin in dried blood spots. Clin Biochem 1990;23:213-19.

Pederzini F, Faraguna D, Giglio L et al. Development of a screening system for cystic fibrosis: meconium or blood screening system for cystic fibrosis: meconium or blood spot trypsin or both? Acta Paediatr Scand 1990;79:935-2. Singer-Sam J, Tanguay RL, Riggs AD. Use of Chelex to improve the PCR signal from a small numb

Amplifications: a forum for PCR users 1989;3:11.
11 Walsh PS, Metzger DA, Higuchi R. Chelex 100 as a medium Walsh PS, Metzger DA, Higuchi R. Chelex 100 as a medium
for simple extraction of DNA for PCR-based typing from forensic material. Biotechniques 1991;10:506-13. 
12 Gasparini P, Bonizzato A, Dognini M, Pignatti PF. Restriction site generating polymerase chain reaction (RG-PCR) for the probeless detection of hidden genetic variation: application mutations. Mol Cell Probes 1992;6:1-7.

13 Rommens J, Kerem BS, Greer W, et al. Rapid nonradioactive detection of the major cystic fibrosis mutation. Am 7 Hum Genet 1990:46:395-6.

14 Chehab FF, Wall J. Detection of multiple cystic fibrosis mutations by reverse dot blot hybridization: a technology

15 Gibson LE, Cooke RE. A test for concentration of electrolytes in sweat in cystic fibrosis of the pancreas utiliz ing pylocarpine by iontophoresis. Pediatrics 1959;23:544-9.

16 Dörk T, Fislage R, Neumann T, et al. Exon 9 of the CFTR gene: splice site haplotypes and cystic fibrosis mutations. Hum Genet 1994;93:67-73.

17 Kiesewetter S, Macek M Jr, Davis C, et al. A mutation in CFTR produces different phenotypes depending on chromosomal background. Nat Genet 1993;5:274-8.

18 Cuppens H, Teng H, Raeymaekers P, De Boeck C, Cassiman JJ. CFTR haplotype backgrounds on normal and mutant CFTR genes. Hum Mol Genet 1994;3:607-14

19 Crossley JR, Elliot RB, Smith PA. Dried-blood spot screening for cystic fibrosis in the newborn. Lancet 1979;i:472-4
20 Rock MJ, Mischler EH, Farrel PM, et al. Newborn screening for cystic fibrosis is complicated by age-related decline in immunoreactive trypsinogen levels. Pediatrics 1990;85:1001-7.

21 Waters DL, Dorney SFA, Gaskin KJ, et al. Pancreatic function in infants identified as having cystic fibrosis in a neonatal screening program. $N$ Engl F Med 1990;322:3038.

22 Pederzini F, Cabrini G, Faraguna D, et al. Neonatal screening for cystic fibrosis using blood trypsin with complementary meconium lactase: an advisable strategy for the population of southern Europe. Screening 1995;3:173-9.

23 Giglio L, Faraguna D, Pederzini F. Neonatal screenig for cystic fibrosis: IRT false positive cases. Proceedings of the
chistio Conference on Mucoviscidose: depistage neonatale et prise en charge precoce, Caen, 1988.

24 Chu CS, Trapnell BC, Curristin S, et al. Genetic basis of variable exon 9 skipping in cystic fibrosis transmembrane conductance regulator mRNA. Nat Genet 1993;3:151-6.

25 Estivill X. Complexity in a monogenic disease. Nat Genet 1996;12:348-50.

26 Pignatti PF, Bombieri C, Benettazzo MG, et al. CFTR gene Pignatti PF, Bombieri C, Benettazzo MG, et al. CFTR gene
variant IVS8-5T in disseminated bronchiectasis. $A m \mathcal{F}$ Hum Genet 1996;58:889-92. 